\title{
Roads at risk: traffic detours from debris flows in southern Norway
}

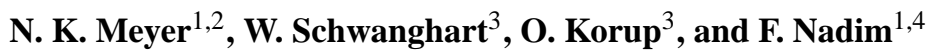 \\ ${ }^{1}$ International Centre for Geohazards (ICG) c/o NGI, Oslo, Norway \\ ${ }^{2}$ University of Oslo, Department for Geosciences, Oslo, Norway \\ ${ }^{3}$ University of Potsdam, Institute of Earth and Environmental Science, Potsdam, Germany \\ ${ }^{4}$ Norwegian Geotechnical Institute (NGI), Oslo, Norway
}

Correspondence to: N. K. Meyer (nelekristin@gmail.com)

Received: 23 September 2014 - Published in Nat. Hazards Earth Syst. Sci. Discuss.: 30 October 2014

Revised: - - Accepted: 1 February 2015 - Published: 19 May 2015

\begin{abstract}
Globalisation and interregional exchange of people, goods, and services has boosted the importance of and reliance on all kinds of transport networks. The linear structure of road networks is especially sensitive to natural hazards. In southern Norway, steep topography and extreme weather events promote frequent traffic disruption caused by debris flows. Topographic susceptibility and trigger frequency maps serve as input into a hazard appraisal at the scale of first-order catchments to quantify the impact of debris flows on the road network in terms of a failure likelihood of each link connecting two network vertices, e.g. road junctions. We compute total additional traffic loads as a function of traffic volume and excess distance, i.e. the extra length of an alternative path connecting two previously disrupted network vertices using a shortest-path algorithm. Our risk metric of link failure is the total additional annual traffic load, expressed as vehicle kilometres, because of debris-flow-related road closures. We present two scenarios demonstrating the impact of debris flows on the road network and quantify the associated path-failure likelihood between major cities in southern Norway. The scenarios indicate that major routes crossing the central and north-western part of the study area are associated with high link-failure risk. Yet options for detours on major routes are manifold and incur only little additional costs provided that drivers are sufficiently well informed about road closures. Our risk estimates may be of importance to road network managers and transport companies relying on speedy delivery of services and goods.
\end{abstract}

\section{Introduction}

Society's reliance on transport networks has grown extensively, commensurately amplifying potentially adverse consequences of network malfunction (Taylor and D'Este, 2003; Demšar et al., 2008; Andrey, 2010). Linear infrastructures such as road and rail networks, pipelines, and power grids are sensitive to catastrophic disruption (Schulz, 2007). Such network failure can be caused by, among others, vehicle accidents, construction work, natural hazards, and terrorism (Tacnet et al., 2012). These incidents can result in reductions or interruptions in serviceability and thus determine the reliability of a network (Berdica, 2002). Transport network reliability is the degree of certainty with which travel between $\mathrm{A}$ and $\mathrm{B}$ within the time period $\mathrm{t}$ is possible (Immers et al., 2004); reliability is a function of the likelihood that an incident will cause network malfunctioning and is determined by the likelihood of the incidence itself and the robustness of the network against failure (Murray and Grubesic, 2007). Network vulnerability analyses relate this likelihood of failure to its economic and societal consequences (Jenelius, 2009). Most road network analyses are concerned with urban networks where traffic interruption often leads to congestion affecting a large number of people (Taylor and D'Este, 2003; Appert and Chapelon, 2013). However, in mountainous areas traffic disruption due to natural hazards such as landslides may also present a threat to human life and cause significant delays, reduced accessibility, and high economic costs (Scott et al., 2006). Recent statistics suggest that $\sim 45000 \mathrm{~km}$ of road and railways are exposed to landsliding worldwide (Dilley, 2005). Hence, there is increasing demand for quantitative 
studies that assess the transport network analyses on interregional and national scales (Taylor et al., 2006).

In this study we focus on quantifying the risk of traffic network downtimes caused by natural hazards and draw on the example of major roads in Norway. The following case illustrates the need for appraising the consequences of road closure: a flash flood in July 2006 washed away $30 \mathrm{~m}$ of the highway E14 that connects Östersund in Sweden and Trondheim in Norway and sustains daily traffic of 1000 2000 vehicles/day. The shortest detour between both ends of the washed out road section was $>200 \mathrm{~km}$; partial reopening of the road took 12 days. The estimated costs of repair were EUR 1.2 million (Jenelius, 2010). Yet this assessment failed to allocate costs for additional travel time and fuel consumption required to circumnavigate the closed road. A calculation that assumes an average fuel consumption of $6 \mathrm{~L} / 100 \mathrm{~km}$ and a fuel price of EUR $1.5 \mathrm{~L}^{-1}$ would incur additional costs of between 216000 and EUR 432000 , or up to $45 \%$ of the structural damage. This simplified calculation merely takes addition fuel consumption into account and illustrates important costs often neglected in assessing road damage and calls for further enquiry. Moreover, other costs related to work time loss and/or delays in delivery (especially perishables) are not considered. These may add even higher additional costs than computed for fuel consumption.

Norway's steep topography and high frequency of extreme weather events expose a large portion of its transport infrastructure to natural hazards (Bargel et al., 2011; Bjordal and Helle, 2011; Norem and Sandersen, 2012). Norway is a large and sparsely populated country, and roads crossing remote parts are often the only connection between larger cities (Fig. 1). Hence, unanticipated detours often involve long additional distances. Moreover, the demand for road serviceability has increased notably in the last decades. The total annual person transport carried out by private cars in Norway had doubled to $\sim 80 \%$ by 2002 as compared to 1960 . During the same period, the volume of transported goods increased 9-fold and remains the dominant mode of land transport in Norway (Boge, 2006). Mountain valley floors collect most of the incoming natural water and sediment fluxes. Roads located in such valleys are often affected by rapid mass movements that degrade roads and interrupt traffic flow (Winter et al., 2008). While rockfalls and snow avalanches are most frequent disturbances, the rarer debris flows were responsible for the majority of all pavement damages related to mass wasting from 2006 to 2009 (Bjordal and Helle, 2011). Even though this study quantified structural damages to road infrastructure from natural hazards, we are not aware of any analysis of the overall functional value of the road network in Norway.

Here our aim is to merge graph theory and quantitative risk assessment to quantify the functional impact of debris flows in terms of road closure and associated risks for the south Norwegian road network (Fig. 1). We use a two-step approach. First, we gauge the likelihood of debris-flow oc-

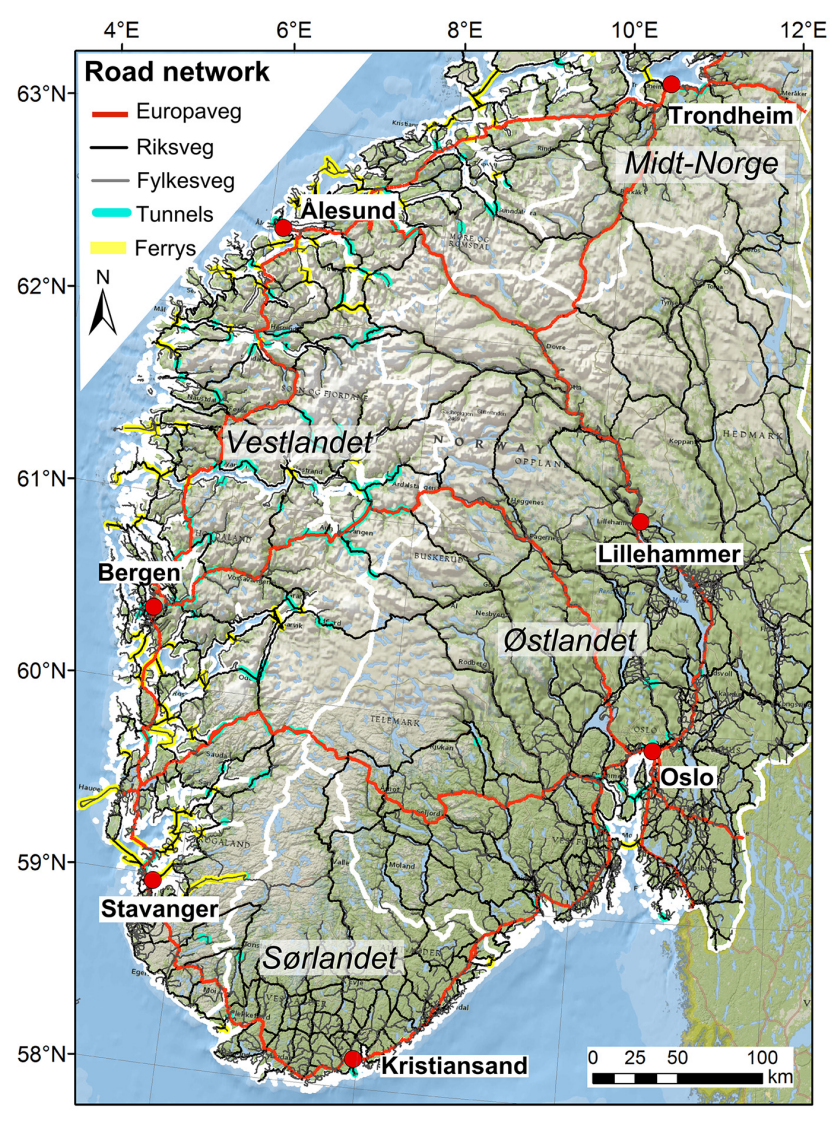

Figure 1. Study area and road network connecting major cities in southern Norway. All traffic data were provided by the Norwegian Public Road Administration Statens Vegvesen. Road characterisation and regions delineated by white boundaries correspond to Norwegian nomenclature.

currence in first-order catchments to determine, on a statistical basis, how frequently roads need to be shut down in consequence. Second, we estimate the functional value of the roads rather than their structural damage. We express this functional value as the calculated total additional traffic load resulting from road closures and assess the ensuing risk in terms of total excess road kilometres per year. We conclude by highlighting potential network weaknesses tied to two different debris-flow scenarios.

\section{Data}

With an area of $\sim 320000 \mathrm{~km}^{2}$ mainland Norway extends over nearly $1800 \mathrm{~km}$ in a north-south direction $\left(57^{\circ} 57^{\prime} \mathrm{N}\right.$ to $71^{\circ} 11^{\prime} \mathrm{N}$ ). About $30 \%$ of the country features mountainous areas with steep slopes and harsh climatic conditions (Fischer et al., 2012). The annual precipitation may exceed $4000 \mathrm{~mm}$ on the west coast, and the annual mean temperature ranges between $-8^{\circ} \mathrm{C}$ in northern and central southern Norway and $+8^{\circ} \mathrm{C}$ along the southern coast (Dyrrdal et al., 2012). We fo- 

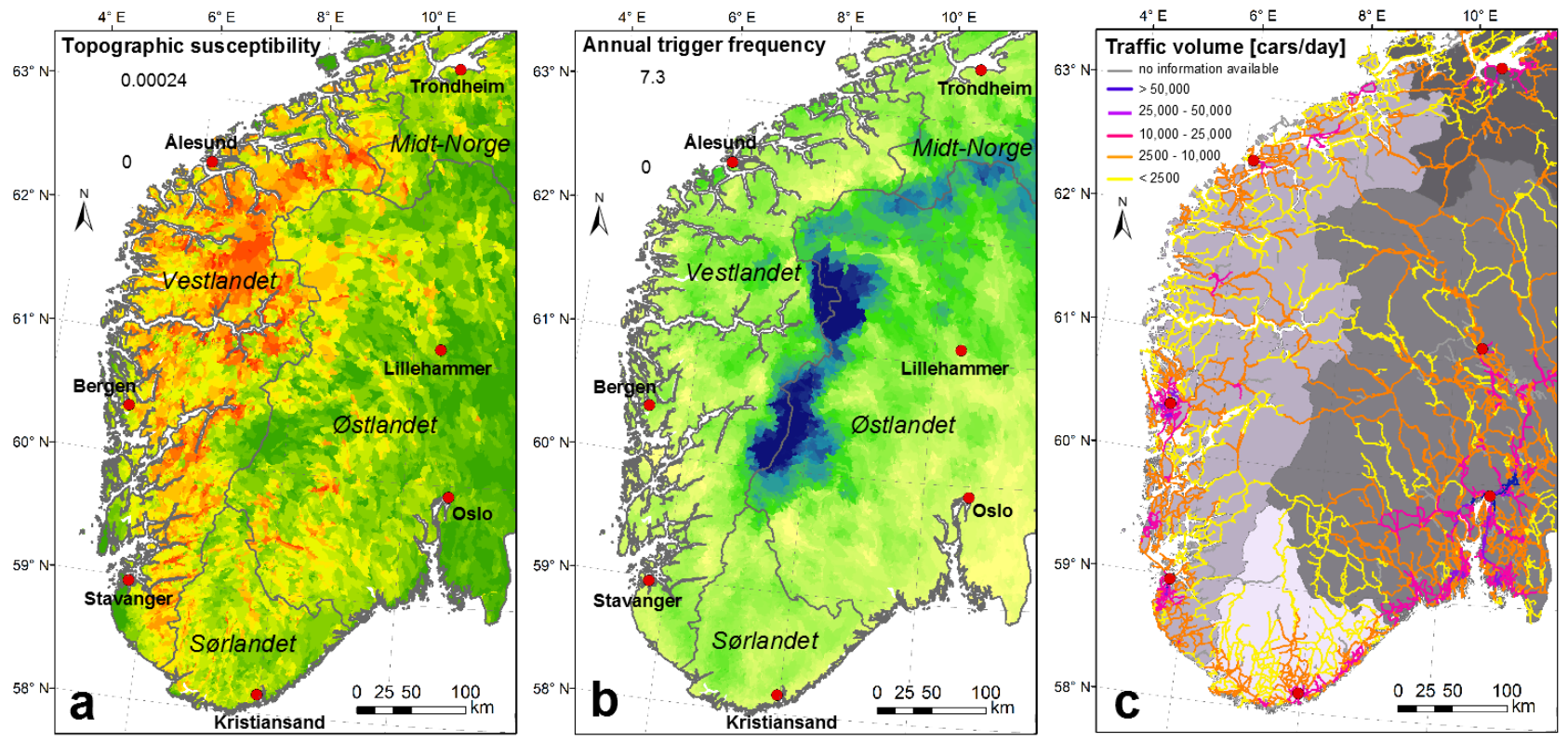

Figure 2. (a) Topographic susceptibility, i.e. aggregated probability of debris-flow occurrence, in first-order catchments; (b) annual trigger frequency in first-order catchments; (c) average traffic volume per day.

cus on the area south of $64^{\circ} \mathrm{N}$, which covers the four regions of Vestlandet, Sørlandet, Østlandet, and Midt-Norge (Fig. 1). Several mountain regions form a major divide between Vestlandet and Østlandet, promoting maritime and continental climates respectively.

Our analysis covers $>40000 \mathrm{~km}$ of road network. Europavegs are the main arterial roads that connect the different regions, whereas Riksvegs and Fylkevegs are regional and local roads respectively (Fig. 1). We disregarded smaller urban roads not contributing to the regional or interregional connectivity. Norwegian roads have a maximum speed limit of $80-100 \mathrm{~km} \mathrm{~h}^{-1}$ and usually consist of one track in each direction but are multi-tracked close to the main cities. In more densely populated areas and along the coast the network density is high, while the mountainous area in the central part of the study area has a thin road network.

Our analysis draws from previous work on a topographic susceptibility model for debris-flow source areas (Meyer et al., 2014) and a threshold model specifying hydrometeorological conditions needed to trigger debris flows (Meyer et al., 2012). Both models are calibrated and validated with a national mass-movement database featuring $>500$ debris-flow events recorded between 1979 and 2008 (http://www.skrednett.no/; Jaedicke et al., 2009; Meyer et al., 2012, 2014). The topographic susceptibility is based on a weights-of-evidence model using the two topographic parameters of slope and flow accumulation with a resolution of $25 \mathrm{~m} \times 25 \mathrm{~m}$. This model identifies potential debris-flow source areas and assigns spatial probabilities to each grid cell. Susceptibility to debris-flow initiation is high where steep slopes $\left(\sim 20\right.$ to $\left.\sim 60^{\circ}\right)$ and contributing areas of $\sim 0.02$ to $2 \mathrm{~km}^{2}$ combine, i.e. mainly in the fjord landscape along the west coast.

Trigger frequencies rely on an intensity-duration threshold derived from past hydro-meteorological conditions (Meyer et al., 2012). In Norway, such critical hydrometeorological conditions are usually tied to heavy rainfall and intense snow melt. Thresholds are ranked (minimum, medium, and maximum) at $1 \mathrm{~km} \times 1 \mathrm{~km}$ resolution and normalised by the precipitation day normal to account for differences in the climatic regime. We use the diurnal medium threshold and calculate the mean annual trigger frequency for the period 1981-2010 (Meyer et al., 2012).

For this study, we spatially aggregated the gridded data on topographic susceptibility and annual trigger probability within first-order catchments (http://atlas.nve.no; Fig. 2a, b). First-order catchments are the smallest hydrometric reference areas in the officially used national catchment database REGINE and have a median area of $8.5 \mathrm{~km}^{2}$. We multiplied the fraction of terrain susceptible to debris flows with the associated probability of occurrence for each first-order catchment. The topographic susceptibility is highest in Vestlandet but decreases to the east with lower topographic relief (Fig. 2a). We spatially averaged the annual trigger frequency of all pixels within each catchment. Trigger frequencies are highest on the plateaus between Vestlandet and Østlandet and may reach more than seven triggering events per year (Fig. 2b).

We assess the daily traffic volume per road from data by the Norwegian Public Road Administration Statens Vegvesen (Fig. 2c). Traffic volumes are high in urban areas and along the coast where the population density is highest. 


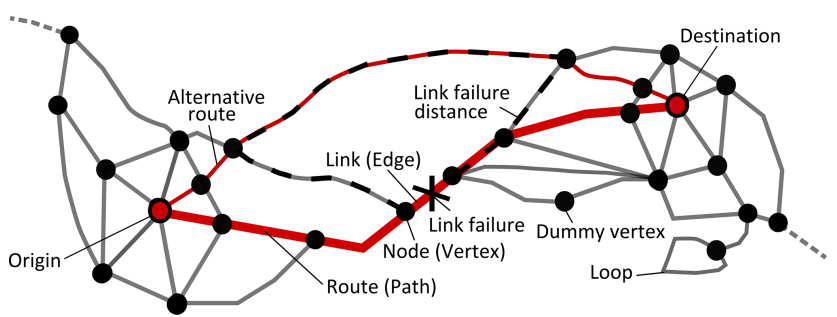

Figure 3. Example of a road network including terms used in this study.

There, route sections are frequented commonly by $>10000$ cars/day. Around Oslo, the capital and largest city of Norway, average traffic per day exceeds 50000 cars/day, whereas the mountainous core of the study area has much lower volumes $(<2500$ cars/day). Data on traffic volumes are available for $\sim 93 \%$ of the studied roads.

\section{Methods}

\subsection{Graph theory}

We use graph theory for quantifying likely impacts of debris flows on Norway's road network. In the following we briefly review some basic terminology, algorithms, and assumptions pertinent to our application of graph theory and road networks. For a more detailed introduction into graph theory we refer to Gross and Yellen (2005) and Heckmann et al. (2015). A graph $G(V E)$ is the mathematical representation of a network defined by two disjoint sets of vertices $V$ and links $E$. A link is defined by two vertices $u$ and $v$, and two vertices are adjacent to each other when a link $\{u, v\}$ connects them. The topology of a graph is stored in an adjacency matrix with $n$ rows and $n$ columns, where $n$ is the number of vertices in the network. An element in row $u$ and column $v$ in the adjacency matrix is unity if there is a link between $u$ and $v$; otherwise the element is zero. We make the simplifying assumption that all links can be traversed in both directions. Hence, our road network is an undirected graph and the associated adjacency matrix is symmetric with respect to the main diagonal. Vertices represent either road junctions or dead ends and thus have 1,3, or more incident links (or vertex degrees). We deviate from this definition in cases where two or more distinct roads share the same pair of nodes by introducing two-degree dummy vertices (Fig. 3). When calculating the adjacency matrix of the road network, these dummy vertices avoid the collapse of two or more links into a single link. We furthermore did not include any loops, i.e. links with both ends sharing the same vertex.

Each road link has metric attributes such as length and traffic volume that we used as weights in a shortest-path calculation. A path or route is a sequence of vertices connected by links with no vertex being visited more than once (Demšar et al., 2008). An origin vertex is connected with a destination vertex if there is a path between them (Fig. 3). The shortest path is the route between two vertices that minimizes the sum of weights. We assume that all motorists choose the path with the shortest total travel distance between two road junctions. Reorganisation of a shortest path between two vertices is required if a link fails due to debris-flow impact and subsequent road closure (Fig. 3). We assume that if this were the case for a link belonging to the shortest path, motorists would use the shortest alternative route. Thus, our simulation emulates the functioning of vehicle navigation systems that in fact rely on a similar set of graph theoretic algorithms. We refer to excess distance as the difference between the shortest detour path and the original distance along a blocked road link. We compute excess distance for each link in the road network by setting the respective element in the distance matrix to zero and then reassessing the shortest alternative path. The distance matrix resembles the adjacency matrix, but its nonzero elements contain the travel distance between two adjacent vertices. Excess distance is a local measure expressing the length of detour between two adjacent vertices, whereas the total detour around a blocked road may be lower if the distance between origin and destination allows for more optimal alternative routes (Fig. 3). We focus on the road network connecting the seven major cities in southern Norway, i.e. Oslo, Lillehammer, Trondheim, Ålesund, Bergen, Stavanger, and Kristiansand. We used MATLAB version R2012a (The MathWorks, 2012) and MatlabBGL, a toolbox that interfaces with the Boost Graph Library (Siek et al., 2001) for our network analysis, and Dijkstra's algorithm to compute the shortest paths.

\subsection{Risk framework}

We assess the probability and consequences of link failure within the risk framework. In its most general form, risk $R$ can be defined as $R=H \times C$, where $H$ is the probability of a threatening event (hazard), and $C$ are the consequences related to $H$. The consequences $C$ are a product of the value of the elements at risk $E$ and their vulnerability $V$ such that the risk equation becomes $R=H \times \mathrm{E} \times V$. Vulnerability $V$ is a factor between 0 and 1 , indicating the severity of expected loss given a hazard $H$, and expressed as a fraction of the total value of $E$. In the context of network vulnerability, monetary values of road segments (pavement, side rails, etc.) can be included to refer to the structural vulnerability of the elements at risk. Hazard $H$ may express the probability of occurrence of a potentially damaging phenomenon within a given time period and area (Downing et al., 2001). We approximate $H$ by computing the likelihood of debrisflow occurrence (Fig. 4) as the product of the topographical susceptibility (Meyer et al., 2014) and the annual trigger frequency for each first-order catchment (Meyer et al., 2012). We did not convert this likelihood to a normalised probability in order to preserve information about the annual triggering 


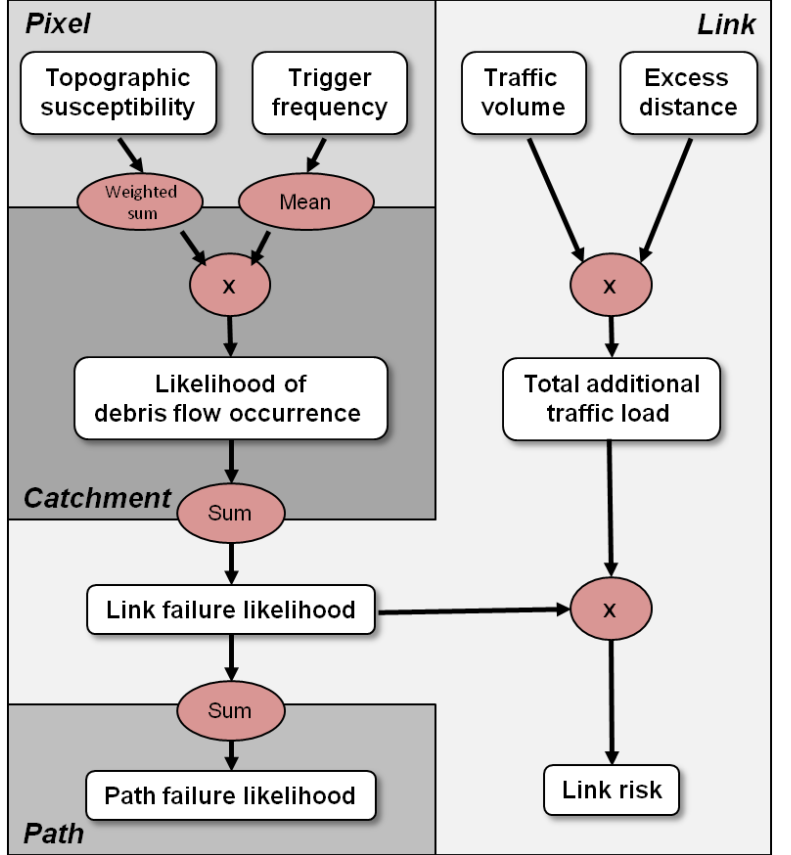

Figure 4. Flow chart showing aggregation and processing of data on different scales: pixel, catchment, link, and path. For detailed description of aggregation process see text.

frequency. In any case, the shape of the probability distribution of $H$ remains the same. We then assigned the likelihood of debris-flow occurrence in each catchment to the adjacent road links. In cases where a road link intersected with more than one first-order catchment, we used the sum of topographical susceptibilities times the highest trigger frequency along the respective road link (Fig. 4). Thus, derived linkfailure likelihoods reflect the assumption that debris flows occurring in small mountain catchments reach and take out the road for 1 day eventually. Hence, we assume a link vulnerability of unity. This is a strongly simplified assumption as not all debris flows in these catchments will cause equal damages on roads and may be subject to different closure times accordingly. However, besides practical reasons this assumption seems reasonable given that our analysis is based on debris flows that had impacted roads in the past. We set the likelihood to zero for ferry connections and tunnels longer than $1 \mathrm{~km}$ as we assume these reaches are safe from debrisflow impact. However, we do not consider existing mitigation measures that protect roads from the impact of debris flows. We note that our use of link-failure likelihood is equivalent to the complement of link reliability, a term commonly used in transport network analysis (Murray and Grubesic, 2007; Boge, 2006). We preferred the term likelihood to keep the term consistent with related measures on catchment and path level used in our analysis (Fig. 4).

Our attention is on expenditures in terms of additional traffic loads resulting from road closures and thus the functional

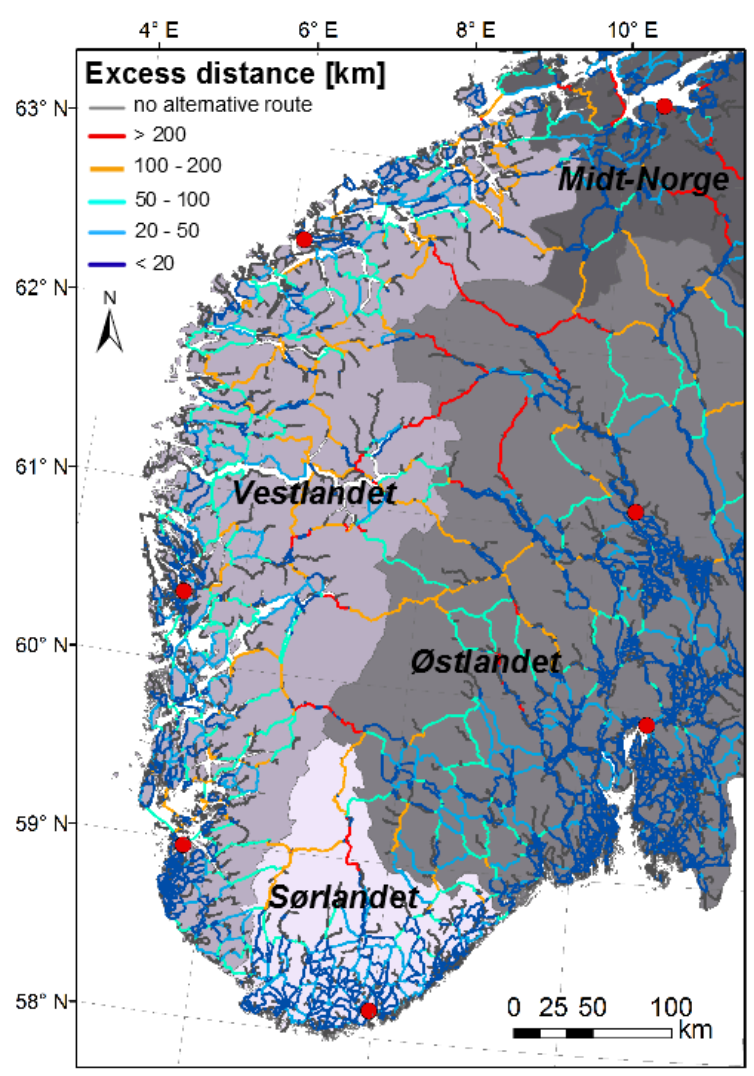

Figure 5. Excess distances resulting from potential road closures.

value of the network links. The product of traffic volume (vehicles/day), excess distance $(\mathrm{km})$, and closure time (days) gives the total additional average traffic load per road closure (vehicles $\times \mathrm{km}$ ) (Fig. 4). Assuming that characteristic closure times amount to 1 day, we multiply link-failure likelihood $\left(1\right.$ year $\left.^{-1}\right)$ with additional traffic load to obtain the annual debris-flow-related link risk (vehicles $\times \mathrm{km}$ year ${ }^{-1}$ ) (Fig. 3). We explore the applicability of this approach in two scenarios. The simpler scenario involves road closure and subsequent traffic diversion by a single debris flow. An alternative scenario is informed by the historical mass-movement database (http://www.skrednett.no/; Jaedicke et al., 2009). This inventory indicates that extreme weather events often trigger multiple debris flows; 667 documented debris flows were associated with 285 triggering events such that one rainfall or snow-melt event triggered more than two debris flows in average.

\section{Results}

\subsection{Link risk analysis}

Our network analysis shows that computed excess distances are longest $(>200 \mathrm{~km}$ ) through the central part of the study area (Fig. 5). Short alternative routes are available near 

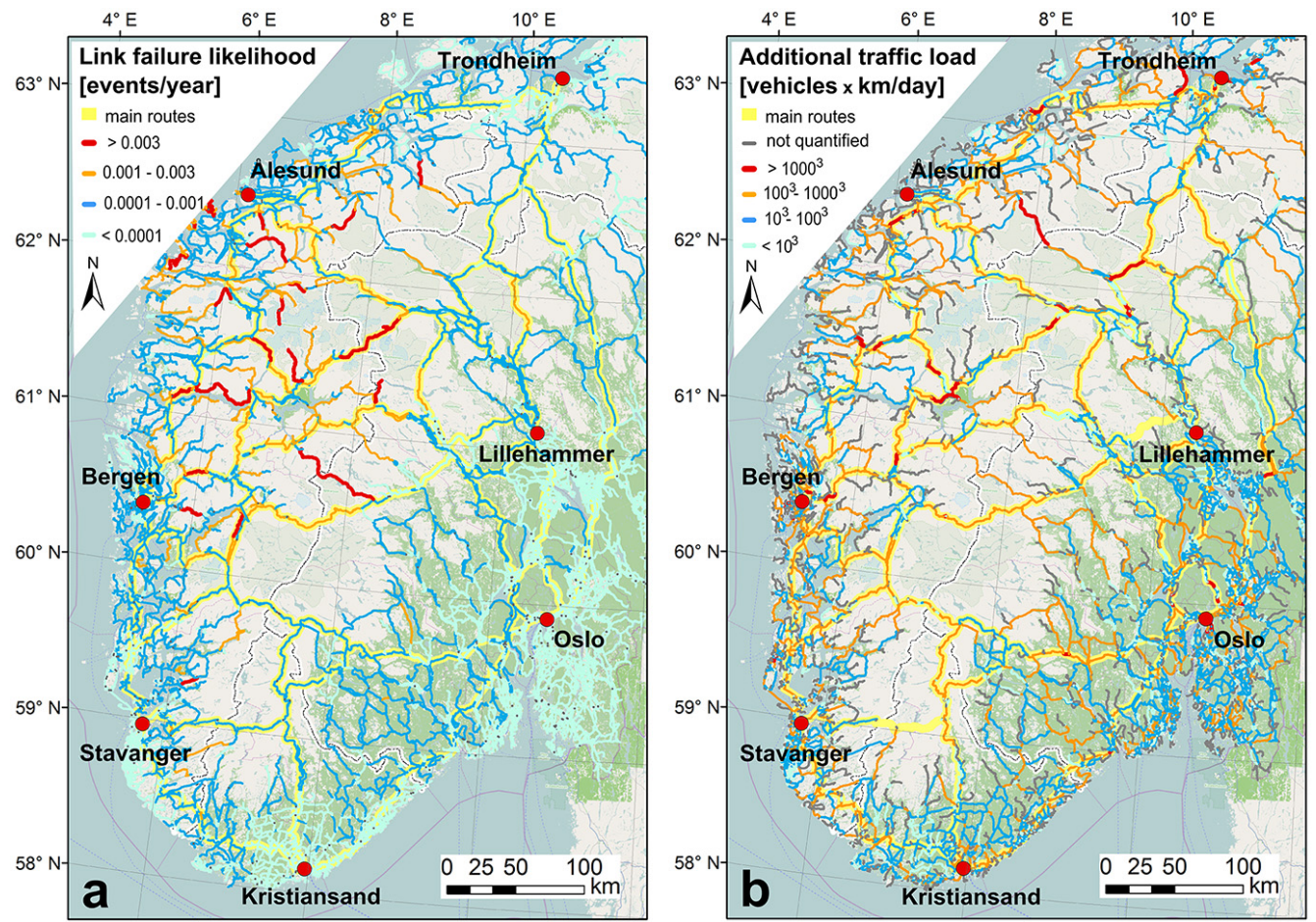

Figure 6. (a) Link-failure likelihood and (b) total additional traffic load per road closure; main routes between seven large cities in southern Norway are marked in yellow.

Table 1. Matrix of distances on main routes $(\mathrm{km})$ between major cities (lower left) and the associated total path-failure likelihood (event/year) (upper right); cells are highlighted in bold according to quartile-based classification of failure likelihood.

\begin{tabular}{lrrrrrrr}
\hline & Kristiansand & Stavanger & Oslo & Trondheim & Bergen & Lillehammer & Ålesund \\
\hline Kristiansand & 0 & 0.010 & 0.014 & 0.024 & 0.038 & 0.022 & 0.072 \\
Stavanger & 245 & 0 & 0.019 & $\mathbf{0 . 0 8 2}$ & 0.029 & 0.032 & $\mathbf{0 . 0 9 3}$ \\
Oslo & 317 & 447 & 0 & 0.010 & 0.034 & 0.005 & 0.062 \\
Trondheim & 806 & 816 & 490 & 0 & $\mathbf{0 . 0 8 4}$ & 0.016 & 0.036 \\
Bergen & 453 & 209 & 470 & 637 & 0 & 0.064 & 0.070 \\
Lillehammer & 466 & 548 & 167 & 342 & 433 & 0 & 0.061 \\
Ålesund & 762 & 590 & 531 & 335 & 381 & 370 & 0 \\
\hline
\end{tabular}

cities and along the coast. Longer detours also characterise road sections along the Swedish border, although alternatives become available there when the Swedish road network is used. The link-failure likelihood varies between 0 and 0.02 events/year and is highest in the north of Vestlandet (Fig. 6a), largely mimicking the topographic susceptibility (Fig. 2a). Similarly, higher trigger frequencies along the mountain plateaus contribute to an increase of this likelihood (Fig. 2b).

The total additional traffic load per road closure varies widely between $10^{1}$ and $>10^{6}$ vehicle $\mathrm{km}$ per day (Fig. 6b). The highest loads may occur not only in the mountainous interior of the study area where road density is low and excess distances are high but also near cities and along the coast with commensurately high traffic volumes (Fig. 2c). We computed the maximum loads for a road section stretching from Trondheim towards the Swedish border. In addition to a large traffic volume of $>25000$ cars/day, the excess distances are quite large $(>300 \mathrm{~km})$ along this section.

A high annual debris-flow-related link risk of $>1000$ vehicle $\mathrm{km}_{\text {year }}{ }^{-1}$ characterises Vestlandet (Fig. 7), an area that combines high topographic susceptibility, hydro-meteorological trigger frequencies, and long excess distances. High traffic volumes near Bergen and Alesund exacerbate this risk. Parts of main routes linking the larger cities are also tagged with high risks: 56 out of the 100 links with the highest link risks are located on the main routes.

Summing up the link-failure likelihoods along routes between major cities in the study area, we obtain the total path-failure likelihood (Table 1). In this regard, the main 


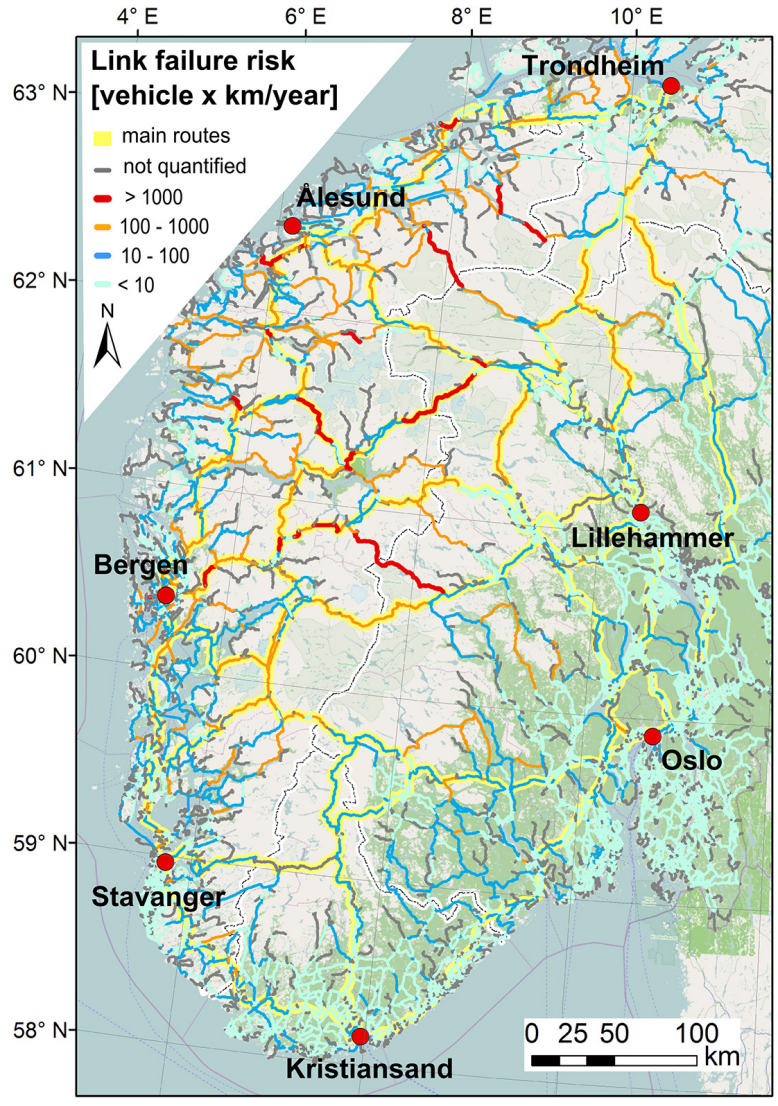

Figure 7. Estimated annual link risk expressed as vehicle km; main routes between seven large cities in southern Norway are marked in yellow.

route between Ålesund and Stavanger has the highest likelihood of being blocked by debris flows with an average return period of $\sim 10$ years. A comparable blockage potential characterises the routes Trondheim-Bergen, and TrondheimStavanger. Similarly, all routes crossing the mountainous interior in north-south or west-east direction have higher pathfailure likelihoods than routes circumventing this area.

\subsection{Scenarios}

Two scenarios highlight the applicability of our approach. In Scenario 1, we identified a $75 \mathrm{~km}$ long road section on Riksveg 55 between Lom and Skjolden as the section with the highest link-failure likelihood, which we expect occurs every $\sim 50$ years on average. Riksveg 55 is one of the main interregional connections between Bergen and Trondheim used by $\sim 4000$ cars/day. The scenario involves a road closure between Lom and Skjolden (Fig. 8). The shortest detour between these villages is via Stryn and has an excess distance of $240 \mathrm{~km}$, i.e. more than 3 times the original road section (Fig. 8b). The total additional traffic load would be 960000 vehicle $\mathrm{km}$, assuming 1 day of road closure. Given a fuel consumption of $6 \mathrm{~L} / 100 \mathrm{~km}$ and a fuel price of EUR 1.5/L, this total additional traffic load would incur top-on fuel costs of EUR 86000 . With a return period of $\sim 50$ years, the expected annual detour costs are EUR 1720 for this road section only on the premise that motorists take the calculated detour route irrespective of their origin and destination (blue route, Fig. 8b). However, the shortest detour between Bergen and Trondheim would not pass either Lom or Skjolden. The alternative quickest route has an excess distance of $67 \mathrm{~km}$, incurring additional fuel costs of $\sim$ EUR 20000 , assuming a daily traffic volume of 4000 cars between Bergen and Trondheim (yellow route, Fig. $8 b$ ).

In Scenario 2, western Norway (Vestlandet) was hit by extreme rainfall brought by low "Kristin"; local rainfall on 14 September 2005 exceeded $100-200 \mathrm{~mm}^{-1}{ }^{-1}$ (Sletten, 2009). The area around Bergen experienced particularly heavy rainfall that triggered a large number of debris flows. At least 49 of these caused documented traffic disruption on several roads and railways. In Bergen, 3 people died, 7 were injured, and 152 were evacuated (Bargel et al., 2011). Traffic on the main routes between Bergen and cities in the east (Trondheim, Lillehammer, Oslo) were impacted by debris flows, while routes in the west (Ålesund, Stavanger, Kristiansand) remained accessible (Fig. 9a). Excess distances related to these link failures vary considerably between the affected city connections (Table 2); while the detour from Bergen to Oslo is just $13 \mathrm{~km}$ or $3 \%$ longer than the original route, the excess distance for the Bergen-Lillehammer connection is $89 \mathrm{~km}$ or $21 \%$ of original length.

On 15 November 2005, another extreme precipitation event ("Loke") hit the Norwegian west coast (Aall, 2013). Some 63 documented debris flows occurred over a large area in the northern part of Vestlandet, causing massive rail and road traffic delays. Again, main routes between Bergen and eastern cities were disturbed (Fig. 9b), this time also including the main route to Ålesund (Table 2). The computed excess distances from Bergen were between 13 and $67 \mathrm{~km}$ to Oslo and Trondheim, i.e. 3 and $11 \%$ larger than the original distances respectively (Table 2).

\section{Discussion}

We quantified the failure likelihood of road links potentially impacted by debris flows in southern Norway by merging estimates of topographic susceptibility and hydro-meteorological trigger frequency. The national massmovement inventory (http://www.skrednett.no/; Jaedicke et al., 2009) gives some insight into past road closures by debris flows: data from 2003 to 2007 demonstrate that the road links most frequently impacted by debris flows have a substantially higher failure rate than our computed minimum return period of $\sim 50$ years suggests. The 4 years of detailed data coverage, however, fall short of offering substantial validation of our model concerning the simulated failure likelihoods. These 

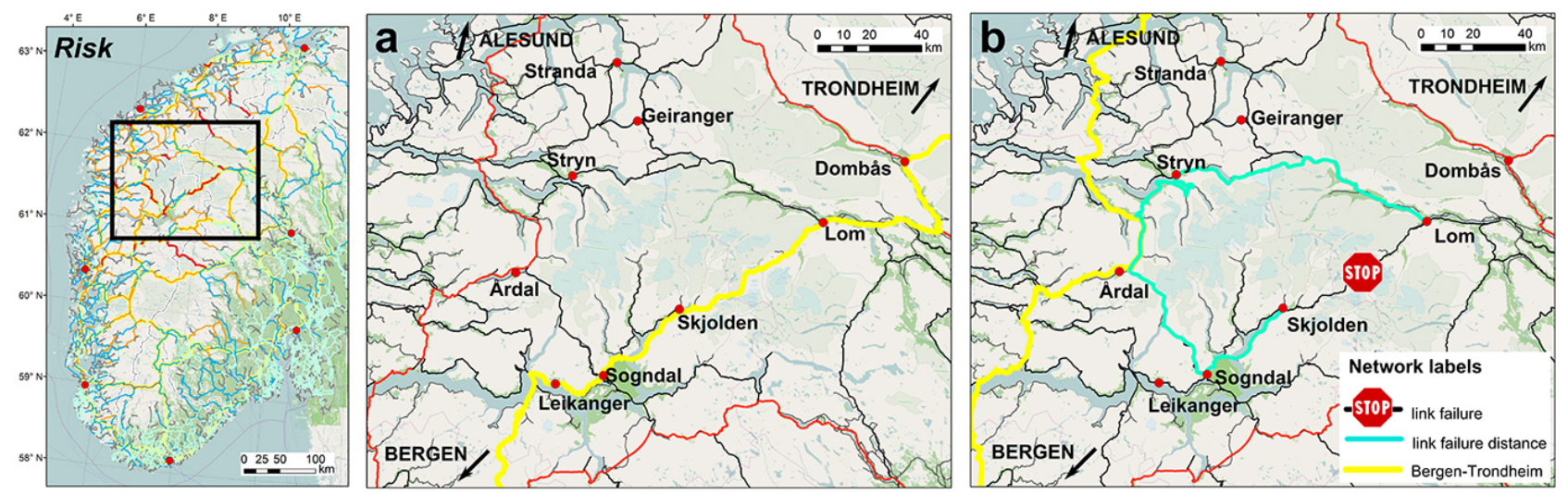

Figure 8. Illustration of network routing with (a) open access between Lom and Skjolden and (b) under temporary closure of road between the two cities. Legend to overview map is given in Fig. 7.

underestimates may partly result from a general improvement of the reporting quality from 2003 to 2007 as opposed to the preceding years used for model training. Nevertheless, the computed link-failure likelihoods are an unprecedented attempt to rank at the regional scale the road-network segments according to their propensity of disruption. This information is vital concerning potential debris-flow impacts and is extensible to other, more frequent, processes such as snow avalanches and rockfalls that share similar topographic and climatic prerequisites (Slaymaker, 2010). Clearly both appraisals of the susceptibility and triggers of snow avalanches and rockfall would need due adjustment if added to our network analysis. However, the results of our analysis present a first step towards a more comprehensive risk assessment that includes the risk related to functional damages exemplified by one specific type of rapid mass movement.

We quantified the failure likelihood for the shortest paths between major cities in southern Norway, namely Oslo, Lillehammer, Trondheim, Ålesund, Bergen, Stavanger, and Kristiansand. However, we did not account for temporary closure during winter months, which is common for parts of these connections. Hence, the seasonal occurrence probability of debris flows may modulate our assessment of link- and path-failure likelihoods. Given that most documented debris flows occurred in autumn, whereas winter months are less affected by debris flows and related road closures, we surmise that our annual likelihoods are minimum estimates. The available data on daily traffic volume are averages, however, and thus do not allow resolving any temporal pattern.

Our computed excess distances relate necessary detours around a failed road link to the original distances and draw on graph theory, which is a common, straightforward, and mathematically rigorous method used in network analysis (Holmgren, 2006; Grubesic et al., 2008). This approach requires a well-documented road network without any topological errors (Erath et al., 2009). International road connections may compromise this analysis: along the Swedish border the com- puted excess distances are biased because we miss possible shorter detours that make use of the Swedish road network. Including the road networks beyond national borders is likely to yield more robust results for some of the excess distances.

Our method of computing excess distances relies on topology but may neglect a number of alternative options of dealing with closed roads. Two cases require that the entire distance of the alternative route connecting both ends of the link needs to be passed without much alternative: (1) regional travellers have the two end vertices of the failed link as origin and destination, or (2) interregional travellers are not aware of the road closure until they reach the disrupted link in question. However, motorists' knowledge about specific traffic conditions regarding potential detours is another point that may compromise the validity of computed excess distances (Lyons, 2006; Nyblom, 2014): drivers may be informed about road closures well in advance and choose alternative routes that deviate from the vertices enclosing the impassable road. This information status depends, among others, on the time between the announcement of road closure and the onset of journey, the distribution and reception of information by authorities, and the technical capability of drivers to receive this information. Our scenario-based assessment of such alternative paths between larger cities in southern Norway demonstrates that prior knowledge concerning road closures leads to significantly reduced excess distance (Fig. 4). Scenario 1 indicates that the ratios of excess distances to the original travel distance are larger for regional than interregional traffic. Scenario 2 also illustrates that multiple link failures may prolong the shortest path between cities in few cases only, e.g. in September 2005 between Bergen and Lillehammer. These results hinge on the assumption that travellers are informed about road closures and alternative paths do not suffer from subsequent failures.

We stress that our network analysis focuses on the total additional traffic load per road closure and not on any additional costs incurred by structural road damage. Clearly, the total 
Table 2. Distances between Bergen and other cities with intact road network and excess distances following road closures specified in scenarios 1 and 2, given in $\mathrm{km}$. Ratio of excess distance to original route length shown in parentheses.

\begin{tabular}{lrrrrrr}
\hline & Kristiansand & Stavanger & Oslo & Trondheim & Lillehammer & Ålesund \\
\hline Original & 453 & 209 & 480 & 637 & 433 & 381 \\
Scenario 1 & 0 & 0 & $13(3 \%)$ & $32(5 \%)$ & $89(21 \%)$ & 0 \\
Scenario 2 & 0 & 0 & $13(3 \%)$ & $67(11 \%)$ & $48(11 \%)$ & $28(7 \%)$ \\
\hline
\end{tabular}
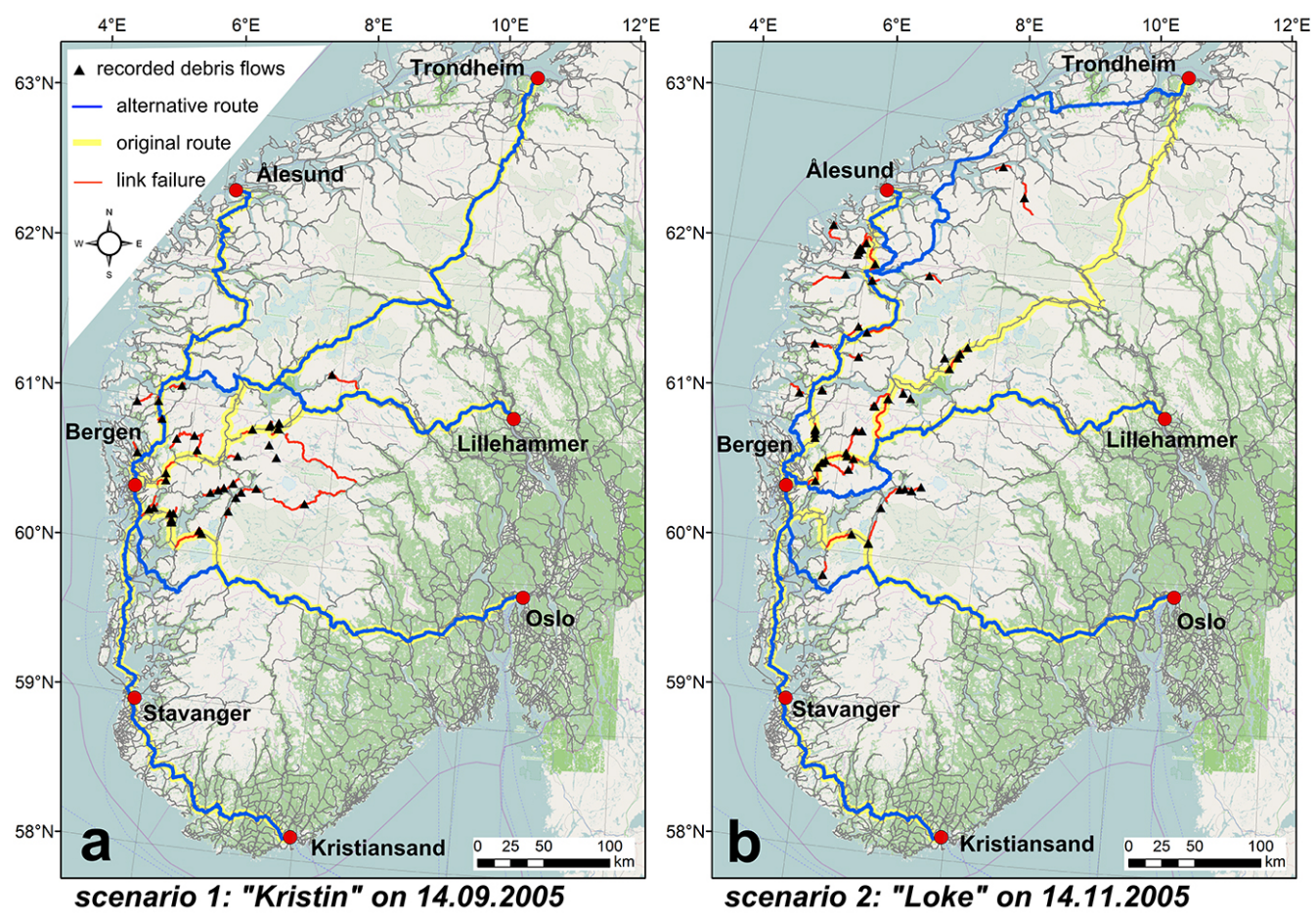

Figure 9. Scenarios investigating effects of extreme rainfall events (a) "Kristin" and (b) "Loke" in 2005 and related debris flows along routes between Bergen and other large cities in southern Norway.

additional costs from detours involve aspects of fuel consumption and availability, actual fuel pricing, driving style, road type, local speed limits, and many others. We refrained from including these parameters in our calculation because of their high variability and favoured casting our risk estimates in vehicle distances per year instead. Fuel consumption is not directly proportional to distance, and actual numbers are subject to rapid price oscillations. However, if reliable information is available, this parameter should be included in the risk calculation to obtain monetary costs associated with detours. We also did not account for the instance that car drivers would occasionally accept small extra distances, e.g. the use of a road instead of a ferry, as waiting times and travel speed will have a direct impact on the overall travel time. Future road-network risk analyses may wish to devote more attention to such effects of alternative transport modes, different road types, etc. on travel time and fuel consumption.

Expressing the link-failure risk in annual vehicle kilometres is the major contribution of our region-wide assessment of the functional value of individual road network segments. This approach goes beyond standard appraisals of road management strategies based on structural values alone. This is because official stakeholders such as road and railway administrations are usually more interested in the structural damage they are paying for (Norem and Sandersen, 2012). Our computed potential costs arising from detours due to debrisflow-related road closures are not included in this bill and are shared amongst individual motorists. However, these external costs are likely to increase if including transport of goods, especially perishables, and delays in delivery in the risk analysis (Bråthen, 2001). While costs related to time delay and fuel may be affordable for the individual, these costs may become critical for companies whose major income depends on the transport industry or the supply of goods (Lakshmanan, 2010). 


\section{Conclusions}

We coupled graph theory with quantitative risk assessment to estimate the annual expected costs of detours arising from road closure by debris flows in southern Norway. A combination of topographic susceptibility and hydro-meteorological trigger frequency in first-order catchments formed the basis for assessing the likelihood of a given road link to fail following debris-flow impact. From this we estimated link-failure likelihoods that, together with data on traffic volumes and computed excess distances, resulted in risk estimates concerning the functional values of road links. We expressed this risk as the expected additional total of annual vehicle kilometres required for detours around closed road sections. Our study concentrated on link-based calculations but also addressed scenarios of path-failure likelihoods between larger cities and effects of debris flows causing multiple road closures.

Debris-flow-related link-failure risk is highest in the mountainous interior of southern Norway, a region that needs to be traversed in order to connect the major cities. This high risk results from high link-failure likelihoods, moderate traffic volumes, and high excess distances. Nevertheless, detour options are manifold for these major trunk routes with only little additional costs provided that drivers are sufficiently well informed about road closures. Our analysis indicates that effective reduction of these costs requires timely publication of information pertinent to road closure. Overall, we estimate this risk at $\sim 10-1000$ additional vehicle kilometres per year. This estimate may be readily converted to monetary costs where data on fuel cost and consumption are available. We stress that these anticipated costs, although likely to be shared by individual motorists, are minimum costs. Companies relying on timely delivery of goods and perishables may wish to consider these and additional costs that arise from undue delays because of debris-flow-related road closure in their risk portfolio.

Acknowledgements. Wolfgang Schwanghart and Oliver Korup acknowledge financial support by the Potsdam Research Cluster for Georisk Analysis, Environmental Change, and Sustainability (PROGRESS). Farrokh Nadim and Nele Kristin Meyer thank the InfraRisk research project and the International Centre for Geohazards (ICG) for the financial support. We thank David Gleich (Purdue University) for providing access to MatlabBGL.

Edited by: F. Guzzetti

Reviewed by: two anonymous referees

\section{References}

Aall, C.: Tilpassing til klimaendringar - frå justeringssamfunnet til transformasjonssamfunnet. Working seminar "Rullering av klimaplan for Hordaland - temagruppe klimatilpassning", Bergen, Presentation, available at http://www.hordaland.no/ PageFiles/53480/KlimaCarloAallN.pdf (last access: 21 February 2014), 2013.

Andrey, J.: Long-term trends in weather-related crash risks, J. Trans. Geogr., 18, 247-258, 2010.

Appert, M. and Chapelon, L.: Measuring urban road network vulnerability using graph theory: the case of Montpellier's road network, HALSHS working paper, 2013.

Bargel, T. H., Fergus, Å. T., Devoli, G., Orvedal, K., Peereboom, I., Øydvin, E. K., Stalsberg, K., Slatten, K., Fischer, L., Rubensdotter, L., and Eilertsen, R.: Plan for skredfarekartlegging - Delrapport jordskred og flomskred, NVE report, Oslo, 16, 2011.

Berdica, K.: An introduction to road vulnerability: what has been done, is done and should be done, Trans. Pol., 9, 117-127, 2002.

Bjordal, H. And Helle, T. E.: Skred og flom på veg., SVV report, Oslo, 5, 2011.

Boge, K.: Votes count but the number of seats decides, Doctoral dissertation, Norwegian School of Management Oslo, 2006.

Bråthen, S.: Do fixed links affect local industry? A Norwegian case study, J. Trans. Geogr., 9, 25-38, 2001.

Demšar, U., Špatenková, O., and Virrantaus, K.: Identifying critical locations in a spatial network with graph theory, Trans. GIS, 12, 61-82, 2008.

Dilley, M.: Natural disaster hotspots: a global risk analysis, World Bank Publications, Washington D.C., 5, 2005.

Downing, T. E., Butterfield, R., Cohen, S., Huq, S., Moss, R., Rahman, A., Sokona, Y., and Stephen, L.: Vulnerability indices: climate change impacts and adaptation, UNEP Policy Series, UNEP, Nairobi, 2001.

Dyrrdal, A. V., Isaksen, K., Hygen, H. O., and Meyer, N. K.: Changes in meteorological variables that can trigger natural hazards in Norway, Clim. Res., 55, 153-165, 2012.

Erath, A., Löchl, M., and Axhausen, K. W.: Graph-theoretical analysis of the Swiss road and railway networks over time, Net. Spat. Econom., 9, 379-400, 2009.

Fischer, L., Rubensdotter, L., Sletten, K., Stalsberg, K., Melchiorre, C., Horton, P., and Jaboyedoff, M.: Debris flow modeling for susceptibility mapping at regional to national scale in Norway, in: Proceedings of the 11th International and 2nd North American Symposium on Landslides, Banff, Canada, 06/2012, 3-8, 2012.

Gross, J. L. and Yellen, J.: Graph theory and its applications, CRC press, Boca Raton, Florida, 2005.

Grubesic, T. H., Matisziw, T. C., Murray, A. T., and Snediker, D.: Comparative approaches for assessing network vulnerability, Int. Reg. Sci. Rev., 31, 88-112, 2008.

Heckmann, T., Schwanghart, W., and Phillips, J. D.: Graph theory - recent developments of its application in geomorphology, $\mathrm{Ge}-$ omorphology, in press, 2015.

Holmgren, Å.: Using Graph Model to Analyze the Vulnerability of Electric Power Networks, Risk Anal., 26, 956-969, 2006.

Immers, B., Stada, J., Yperman, I., and Bleukx, A.: Towards robust road network structures, Slovak J. Civil Eng., 12, 10-17, 2004.

Jaedicke, C., Lied, K., and Kronholm, K.: Integrated database for rapid mass movements in Norway, Nat. Hazards Earth Syst. Sci., 9, 469-479, doi:10.5194/nhess-9-469-2009, 2009. 
Jenelius, E.: Network structure and travel patterns: explaining the geographical disparities of road network vulnerability, J. Trans. Geogr., 17, 234-244, 2009.

Jenelius, E.: Large-scale road network vulnerability analysis, Doctoral dissertation, KTH Stockholm, 2010.

Lakshmanan, T. R.: The broader economic consequences of transport infrastructure investments, J. Trans. Geogr., 19, 1-12, 2010.

Lyons, G.: The role of information in decision-making with regard to travel, IEEE Proc. - Intelligent Transport Systems, 153, 199 212, 2006

Meyer, N. K., Dyrrdal, A. V., Frauenfelder, R., Etzelmüller, B., and Nadim, F.: Hydrometeorological threshold conditions for debris flow initiation in Norway, Nat. Hazards Earth Syst. Sci., 12, 3059-3073, doi:10.5194/nhess-12-3059-2012, 2012.

Meyer, N. K., Schwanghart, W., Korup, O., Romstad, B., and Etzelmüller, B.: Estimating the topographic predictability of debris flows, Geomorphology, 207, 114-125, 2014.

Murray, A. T. and Grubesic, T. H.: Critical Infrastructure, Springer Berlin Heidelberg, 2007.

Norem, H. and Sandersen, F.: Flom- og sørpeskred. Project report "Klima og Transport", SVV report, Oslo, 73, 2012.

Nyblom, Å.: Making plans or just thinking about the trip? Understanding people's travel planning in practice, J. Trans. Geogr., 35, 30-39, 2014.

Schulz, C.: Identification of critical transport infrastructures, Forum DKKV/CEDIM: disaster reduction in climate change, Karlsruhe, 15, No. 16.10, 2007.

Scott, D. M., Novak, D. C., Aultman-Hall, L., and Guo, F.: Network robustness index: A new method for identifying critical links and evaluating the performance of transportation networks, J. Trans. Geogr., 14, 215-227, 2006.
Siek, J. G., Lee, L. Q., and Lumsdaine, A.: The Boost Graph Library: User Guide and Reference Manual, Pearson Education, Upper Saddle River NJ, 2001.

Slaymaker, O.: Mountain hazards, in: Geomorphological Hazards and Disaster Prevention, edited by: Alcántara-Ayala, I. and Goudie, A., 33-48, 2010.

Sletten, K.: GeoExtreme prosjektet. Project seminar "GeoExtreme - endringer i klima og skredfare de neste 50 år”, Oslo, Presentation, available at: http://www.geoextreme.no/seminar.htm (last access: 21 February 2014), 2009.

Tacnet, J. M., Mermet, E., and Maneerat, S.: Analysis of importance of road networks exposed to natural hazards, Proceedings of the AGILE'2012 International Conference on GIS, Avignon, 24-27 April 2012, 370-375, 2012.

Taylor, M. A. and D'Este, G. M.: Concepts of network vulnerability and applications to the identification of critical elements of transport infrastructure, New Zealand Transport Research Forum, 1$15,2003$.

Taylor, M. A., Sekhar, S. V., and D’Este, G. M.: Application of accessibility based methods for vulnerability analysis of strategic road networks, Netw. Spat. Econom., 6, 267-291, 2006.

The MathWorks.: MATLAB, ver 2012a, The MathWorks Inc., Natick, MA, USA, 2012.

Winter, M. G., Macgregor, F., and Shackman, L.: Scottish road network landslides study: Implementation. Summary report, Transport Scotland, 2008. 